\title{
PARTICIPAÇÃO SOCIAL E AUDIÊNCIAS PÚBLICAS NO STF: CONTRIBUIÇÕES A PARTIR DA TEORIA POULANTZIANA DO ESTADO ${ }^{1}$
}

\section{Carolina Alves Vestena ${ }^{2}$}

\section{Resumo:}

O presenta artigo traz uma revisão da discussão sobre a participação social no Supremo Tribunal Federal a partir das audiências públicas. No primeiro bloco, destaca-se a teoria material do estado de Poulantzas (2000), a qual observa o direito e seus aparelhos enquanto estruturas organizadoras do corpo social de acordo com as prioridades das classes posicionadas no bloco do poder dominante. Assim, se oferece uma análise de tais instrumentos como sofisticação do formalismo dos tribunais, ocultando o exercício de controle por mecanismos que concederiam espaço para participação popular e igualariam as oportunidades de intervenção de agentes de diferentes grupos sociais. No segundo bloco, são apresentadas as hipóteses críticas à transferência dos processos políticos para a esfera judicial, fenômeno contemporâneo dos regimes democráticos, conforme abordadas nas primeiras versões da pesquisa discutidas a partir do ano de 2010. A partir de então, reviso os argumentos centrais do debate, retomo as conclusões centrais e destaco diálogos gerados sobre o tema.

Palavras-chave: Supremo Tribunal Federal - Audiências Públicas - Participação Social

\section{INTRODUÇÃO}

Os tribunais têm tido sua relevância acrescida diante das mudanças pelas quais vêm passando as formas de representação política tradicionais. As causas desse fenômeno podem ser imputadas ao atual contexto sóciopolítico no qual se inserem as instituições democráticas. Estas se transformam na medida em que fenômenos como a globalização e a alteração das políticas socioeconômicas passam a exigir novas formas de regulação social e controle do Estado, o que encontra caminho na postura ativa adotada pelas instituições do sistema de justiça, entre elas o próprio Judiciário e o Ministério Público. Como consequência desse fenômeno, no caso brasileiro, um conjunto de alterações tem sido promovido na dinâmica interna dessas instituições, o que se materializa em reformas no âmbito da legislação processual e gestão dos tribunais: a tão comentada Reforma da Justiça.

\footnotetext{
${ }^{1}$ Este artigo resulta da pesquisa realizada no âmbito da pesquisa de mestrado para a obtenção do título de Mestre em Poder Judiciário na Escola de Direito da Fundação Getúlio Vargas, Rio de Janeiro. Outras versões da pesquisa também foram apresentadas em diferentes encontros acadêmicos visando à divulgação dos resultados obtidos.

${ }^{2}$ Doutoranda em Teoria e Filosofia pelo Programa de Pós-Graduação em Direito da UERJ, atualmente realiza período de pesquisa no exterior na Universidade de Kassel, Alemanha, com fomento do Programa PSDE CAPES. E-mail: 
A hipótese central deste trabalho sustenta-se a partir da interpretação de que processos estruturais como a crise do estado e de suas políticas sociais e a globalização econômica podem ser consideradas causas necessárias, ainda que não as únicas, de um processo de ampliação do papel político dos tribunais. Esta leitura é compartilhada por sociólogos como ARNAUD (1999) e SANTOS (1996; 2007). As interpretações brasileiras sobre este fenômeno global somam a estes elementos macrossociais o processo político de consolidação de diretos sociais, bem como a formação da sociedade civil brasileira (VIANNA, BURGOS 2000). Tomo como pressuposto que o processo de expansão do judiciário sobre as esferas sociais torna o campo das instituições judiciais uma arena central de embate social e assume importância para a discussão sobre hegemonia e poder político. O objetivo deste trabalho é levantar pontos de tensão oriundos de uma análise crítica a respeito desse fenômeno.

Nesse contexto de ampliação do sistema de justiça e de políticas institucionais de reforma, as audiências públicas jurisdicionais no Supremo são discursivamente apresentadas como mecanismos judiciais que incrementariam o escopo de atuação e representação política no interior das instituições de justiça a partir da inserção de participação social. Tais audiências foram instituídas no ano de 1997 conferindo aos ministros do STF a prerrogativa de convocação de agentes da sociedade civil para a apresentação de argumentos e opiniões científicas em casos que envolvam grande complexidade. ${ }^{3} \mathrm{Um}$ dos argumentos para sua legitimação é justamente a aposta em suas características democráticas. Esse discurso é proferido majoritariamente pelos próprios membros do Supremo, mas ecoa também nas próprias expectativas da sociedade civil.

Neste ensaio, pretende-se explicitar os limites estruturais de uma suposta democratização pela via participativa no interior dos tribunais. Identificada a emergência do papel do Judiciário frente à política, torna-se necessário compreender como as instituições judiciais se posicionam em determinado contexto social, cujas instâncias políticas e econômicas desempenham fundamental influência nas formas de atuação do Estado e de seus órgãos. Deve-se perguntar: qual o conteúdo democrático concreto que podem assumir as instituições políticas no atual sistema socioeconômico e político? Os tribunais, no interior do Estado, também podem ser configurados como instâncias democráticas? É possível pensar em participação democrática como mecanismo transformador das instituições, especialmente o Judiciário?

Este trabalho será desenvolvido na forma de um ensaio. Portanto, para responder a essas questões, será apresentada perspectiva teórica que observa criticamente as possibilidades de democratização pela via participativa no interior dos tribunais, como um contraponto à teoria dominante que explica e justifica as políticas de reforma. Este trabalho tem por fundamento o pensamento político de Poulantzas, um dos principais teóricos marxistas da década de 70, que escreveu sobre a possibilidade de reconstrução do pensamento marxista para a identificação da política em geral dentro da totalidade do modo de produção capitalista. A principal fonte da obra

\footnotetext{
${ }^{3}$ Para mais pesquisas sobre o tema, ver: (VESTENA 2010; VESTENA 2012; FILHO, Fragale 2013).
} 
poulantziana será sua última obra, "O Estado, o Poder e o Socialismo", de 1978 - neste trabalho, a partir da edição de 2000. Esta escolha se justifica, pois neste livro o autor constrói uma teoria complexa e material da região da política no Estado capitalista, que serve como guia fértil para o estudo do fenômeno contemporâneo da expansão dos tribunais (POULANTZAS 2000; MARTIN 2008). Outras obras do autor serão utilizadas para esclarecer conceitos disseminados no conjunto de seu pensamento. ${ }^{4}$

$\mathrm{O}$ argumento desse artigo se concentra sobre dois aspectos analíticos formulados a partir do pensamento poulantziano a respeito dos limites intrínsecos à participação social no Judiciário. O primeiro apresenta uma crítica estrutural ao papel do direito na sociedade capitalista, o que permite inferir limites determinantes ao recebimento de procedimentos participativos no interior dos tribunais. O segundo elemento analítico a ser destacado diz respeito à perspectiva poulantziana sobre a participação política. Sua análise é contextualizada a determinados regimes de governo conduzidos por políticas consideradas autoritárias ou totalitárias. Nestes contextos, defende que a participação é elemento de controle social dos modelos estatais autoritários, devendo ser, portanto, incentivada e ressaltada no interior de todas as instâncias sociais, de forma autônoma.

O caminho argumentativo aqui adotado tomará por base uma prática jurisdicional inovadora, apresentada socialmente como democratizante das estruturas dos tribunais, para somar novos elementos a uma crítica de conteúdo macrossocial sobre a expansão do Judiciário. Sendo assim, o substrato de análise apresentado pela abordagem materialista impõe uma série de questionamentos a respeito do possível potencial democrático conferido pela participação social no interior dos tribunais. Ainda que fundamentadas em um discurso de democratização e ampla legitimação social, deve-se questionar se as audiências públicas irão efetivamente produzir intervenção qualitativa nas decisões judiciais. Ou se, ao contrário, não passam de mera incorporação pragmática dos pontos interessantes ao conjunto dos votos em questão. Como já destacado, não serão apresentados aqui dados empíricos que reforcem ou rechacem esta abordagem, contudo, a hipótese de trabalho aqui desenvolvida serve como guia para a condução de estudos já realizados - como o que dá base para a discussão aqui apresentada (VESTENA 2010).

Pretende-se observar, à luz da teoria poulantziana, se as audiências públicas jurisdicionais do Supremo, a despeito do discurso democratizante elaborado em seu entorno, não seriam mais do que uma sofisticação de procedimentos formais do aparelho judicial. Em resumo, compreende-se que sua realização reestrutura a ação desse aparelho para garantir uma contenção pretensamente dialética das demandas sociais que, uma vez inseridas

${ }^{4}$ Poulantzas foi um dos principais teóricos marxistas da década de 70. Seu diálogo intelectual foi referenciado especialmente na academia francesa, sendo possível identificar forte influência althusseriana em suas principais obras, que depois foram tomadas por debate crítico com a escola foucaultiana, cujos reflexos foram relevantes no interior de seu pensamento. Costuma-se dividir a obra de Poulantzas em três fases, a sartreana, althusseriana e foucaultiana. Ver em: (MOTTA 2009; MOTTA 2010; MOTTA 2011 la). vol.07, nº. 02, Rio de Janeiro, 2014. pp. 482-508 484 
em seu interior, são limitadas a um debate formal cujo impacto participativo é irrelevante para a tomada de decisão dos ministros ou para alteração das formas jurídicas tradicionais dos tribunais.

Os elementos da teoria poulantziana destacados serão apresentados em passos. Primeiramente, será abordada sua concepção de Estado, demonstrando como esta se tornou mais complexa no conjunto de sua obra. O segundo passo se concentrará na apresentação analítica do direito no interior do Estado, ressaltando as características materializadas nos aparelhos judiciais. Por fim, o terceiro passo consistirá na abordagem da participação, conforme operacionalizada pelo autor, para demonstrar em que medida pode ser considerada atributo essencial para a compreensão de um projeto de sociedade ou de socialismo democrático. Seu conceito transborda os limites das instituições, portanto, supera a ideia de participação como elemento de impacto democratizante no interior dos aparelhos estatais.

\section{QUAL ESTADO? QUAL DEMOCRACIA?}

Os tribunais, objeto deste trabalho, são observados no interior de uma construção macrossocial do Estado, que permite analisá-los enquanto aparelhos manejados em um contexto social, político e econômico específico. Neste sentido, as características que descrevem a estrutura do Estado capitalista conforme e teoria poulantziana lançam luz às possibilidades de análise crítica sobre os processos de democratização no interior das instâncias estatais, dentre elas o aparelho judicial.

A teoria política no modo de produção capitalista de Poulantzas percorre caminhos já desenhados por Marx, quando afirmava a necessidade de retirar o "véu místico" (POULANTZAS 2000, p. 20) que o pensamento liberal dispunha sobre os objetos concretos e as categorias abstratas de pensamento. Uma das conclusões mais relevantes de suas pesquisas foi a observação da complexidade da organização estatal, ao demonstrar que no interior desta instância reproduzem-se as mesmas contradições entre classes presentes nas relações de produção econômica. Segundo o autor, o Estado capitalista seria dotado de uma "ossatura própria", permeada por disputas e conflitos, avanços e retrocessos, que influenciariam as formas de atuação do próprio Estado e das demais instâncias, inclusive a material (IBID., P. 21). Para desenvolver uma teoria própria do Estado capitalista, Poulantzas procura demonstrar uma série de razões que evidenciem as especificidades desta forma política em relação a dominação da classe burguesa. Segundo o autor, "uma evidência fundamental de que este modelo de Estado não é mero instrumento de manipulação pela classe dominante é o de que ele, caso houvesse ruptura política com a conjunção atual de classes, não poderia ser mantido para atender os interesses da então classe dominada, uma vez no poder. Não poderia ser "utilizado de outra maneira mediante uma mudança de poder do Estado, pela classe operária numa transição para o socialismo". Sua estrutura material é responsável pela conexão do Estado e as formas de reprodução da divisão social do trabalho, que no modo de produção capitalista é 
"concentrada na separação capitalista entre produtores, detentores e não detentores dos meios de produção" (IBID., P. 132). Nesse ponto, afastou-se de concepções excessivamente economicistas identificavam as estruturas políticas e seus aparelhos ideológicos e repressivos como meros reflexos da materialidade econômica (SILVEIRA, 1984.p. 13).

Para Poulantzas, a interpretação ortodoxa dos textos marxistas, que historicamente restringia o papel do Estado, servia para aprofundar o processo de ocultação da ocorrência das disputas políticas no interior das próprias relações de produção. Na medida em que essa perspectiva considerava a limitação do desenvolvimento do campo econômico aos rumos traçados por sua auto reprodução, por meio dos diferentes modos de produção, limitava os potenciais embates no plano político e a observação dos processos políticos reais. O desvelar das formas de dominação e contradições no interior da totalidade social somente seria possível com a observação do papel determinante da política no capitalismo (POULANTZAS, op. cit., p. 16).

Poulantzas questionou o pressuposto comum das teorias economicistas centrado na defesa inquestionável da topologia infraestrutura e superestrutura. Essa concepção impossibilitou o destaque do Estado como objeto científico próprio além de ter consagrado a ideia da autonomia entre as esferas sociais. Partindo dessa concepção, todo o esforço teórico teria sido deslocado para a teoria geral da economia, que, segundo estas interpretações, fornecia elementos suficientes para desenvolver os propósitos explicativos de tais variações a partir das relações de produção, relegando a necessidade de uma teoria do Estado (POULANTZAS 1969, p. 15).

Poulantzas afirma que o espaço e o lugar da economia jamais constituíram, nem nos modos de produção pré-capitalistas, nem no capitalismo, "um nível hermético e enclausurado, auto reproduzível e depositário de suas próprias leis de funcionamento" (POULANTZAS, OP. cit., p. 15). Identificou importância constitutiva dos elementos políticos do Estado para as relações de produção (IBID., p. 16). O pressuposto fundamental de sua teoria, a observação de um caráter material no interior do Estado, fez com que o autor reconfigurasse a posição desta instância, de seus aparelhos e, por consequência, redesenhasse suas características dentro da totalidade social. A influência foucaultiana fez com que seu materialismo recebesse uma série de pressupostos relacionais, que tornaram profundamente mais complexa sua análise sobre as formas de poder e atuação das classes no interior do capitalismo. ${ }^{5}$

\footnotetext{
${ }^{5}$ Motta sistematiza a interpretação de Jessop sobre a aproximação gradual de Poulantzas da perspectiva relacional foucaultiana. Critica a interpretação de que Poulantzas em EPS teria retomado origens gramscianas. Para Motta, os trabalhos de Gramsci já fazem parte dos primeiros escritos de Poulantzas. Em EPS haveria, ao contrário, um afastamento parcial de Gramsci. O foco poulantziano se alterna, "partindo da liderança hegemônica de classe em direção a outros dois tópicos: (a) à incoerência prodigiosa das micropolíticas promovidas pelo Estado; e (b) ao papel do Estado na codificação estratégica dessas micro relações. Ele também argumenta que, em geral, não há uma estratégia política global e racionalmente formulada e que a linha geral da dominação política de classe (ou hegemonia?) em geral surge post hoc de uma pletora de micro estratégias e táticas mediadas pelo terreno estrategicamente seletivo do Estado. Isso parece colocar em dúvida o conceito de liderança hegemônica de classe, dissolvendo-o em favor de uma perspectiva mais foucaultiana do que gramsciana” (JESSOP 2009a; MOTTA 201 1a, p. 2). 
A perspectiva do Estado desenvolvida pelo autor serve à observação do objeto do presente trabalho. Ao construir uma teoria política, Poulantzas deteve-se à observação das funções exercidas pelos seus aparelhos, dentre eles os judiciais, no interior do Estado capitalista; além de ter direcionado profunda atenção ao direito enquanto elemento organizador e unificador dos interesses políticos do bloco de poder (MOTTA 201 1B; MOTTA 2010, P. 393). Nesse sentido, as principais características do Estado capitalista são compreendidas para demonstrar como suas estruturas moldam determinadas formas de controle social - seja pela repressão, seja pelo consentimento - para a reprodução de posições sociais de dominação e subalternidade entre classes sociais e suas frações.

Tomando tais elementos, questiona-se: é possível democratizar as instituições jurídicas com a inserção de participação? Como atuam as instituições judiciais no interior do Estado para um projeto político democrático? Como as inovações inseridas pela reforma do Judiciário podem ser interpretadas no conjunto desta teoria? Não seriam as audiências públicas mais um procedimento de contenção social por meio dos aparelhos judiciais?

A fim de responder às questões, o primeiro passo será compreender como se configura o papel do Estado dentro do capitalismo conforme a construção materialista do autor. A análise será concentrada em EPS. Em Poder Político e Classes Sociais (PPCS) é possível identificar uma teoria sistemática para o tratamento científico da política no modo de produção capitalista, que é desenvolvida a partir da articulação e da combinação das instâncias que o especificam. Ao desenvolvê-la, Poulantzas destacou que, no modo de produção capitalista, todas as instâncias - econômica, política, ideológica, etc. - exercem um papel específico, caracterizado por autonomia relativa (POULANTZAS 1969, p. 14).

Poulantzas atribui um papel especial ao Estado no modo de produção capitalista; vê o conceito de autonomia relativa como um elemento concreto, presente nas mediações produzidas entre as diferentes instâncias sociais. A autonomia relativa do Estado, apresentada como uma característica das instâncias do modo de produção capitalista, foi amplamente analisada pelos comentadores da obra poulantziana. Estes buscavam compreender em que medida esta concepção se sustentava frente a teoria marxista e como se diferenciava da concepção epistemológica de cunho althusseriano, linha de influência central no debate travado à época. ${ }^{6}$ Segundo Jessop, o autor procura compreender como a burguesia utiliza o Estado capitalista - o específico

\footnotetext{
${ }^{6}$ Saes, por exemplo, compreende o tratamento da autonomia relativa como um conceito da obra poulantziana fora um erro, posto que "não mereceria mais que um tratamento temático", servindo como base para a exploração de múltiplos registros na obra do autor; para destacar problemas nas leituras marxistas do Estado. Contudo, mesmo que comentadores como Saes diminuam a importância do conceito, observa-se que para o pensamento do autor esta concepção era central. Considerava como pressuposto para a compreensão dos diferentes modos de produção a verificação de uma autonomia real das instâncias políticas na prática social total (SAES 1998, p. 52). Para ver mais sobre as interpretações althusserianas no campo do marxismo brasileiro, ver: (MOTTA 2012)
} 
moderno estado representativo, o Estado-nacional popular de classe - para assegurar sua dominação política (JESSOP 2009b, p. 132).

Já em PPCS, portanto, identificava um papel autônomo na atuação do Estado, localizado dentro da totalidade específica do modelo de produção capitalista, no qual a materialidade das relações de produção, ainda que influenciadas por sua ação, fundam-se no interior dos processos econômicos. Em última instância, o Estado teria o papel de garantir a dominação de classe, porém, sua importância não se restringiria a tal tarefa.

Em EPS, Poulantzas consolida a concepção de que o Estado possui uma "ossatura própria que não é reduzível às relações de dominação política" (POULANTZAS 2000, p. 11). Sendo assim, o problema do Estado consiste em um problema real e, portanto, a compreensão acerca de suas características específicas diz respeito às possibilidades de projeção de análises e propostas para a transição rumo ao regime de socialismo democrático (IBID., P. 12) - ainda que este seja um longo caminho a ser trilhado, sobre o qual, nem o próprio autor produziu análises conclusivas. De toda forma, no contexto da crítica ao modelo político capitalista, Poulantzas afirma que o poder do Estado não está monopolizado exclusivamente e homogeneamente pelas classes dominantes, portanto, nem todas as suas ações reduzem-se à dominação política, ainda que possam ser constitutivamente marcadas por essas características. O Estado reproduz, contudo, de forma particular, o fundamento das relações de produção e a divisão social do trabalho em seu interior (IBID., P. 13).

O reconhecimento das possíveis intersecções entre o Estado e as diferentes instâncias do modo de produção capitalista, e mesmo um processo de determinação recíproca advindo do Estado na atual formação social, somente se tornam possíveis a partir da adoção de um pressuposto crítico em relação às interpretações que veem a economia como sendo "composta de elementos invariantes através dos diferentes modos de produção de natureza e de essência quase aristotélicas, e como sendo auto reproduzível e auto regulável por uma espécie de combinatória interna” (IBID., p. 13). Nesse sentido, mais uma vez se demonstra a forte separação do pensamento poulantziano em relação à perspectiva economicista-formalista.

A configuração material do Estado pressupõe que qualquer alteração de força entre as classes produzirá efeitos no interior das instâncias políticas, uma vez que elas próprias estão contidas no Estado. Contudo, a expressão dessa mudança não ocorre de forma direta. Ela é percebida de forma "refratada e diferencial segundo seus aparelhos" (IBID., Idem). Ou seja, cada âmbito da ossatura material do Estado apresenta uma série de contradições internas, a partir de diferentes frações do bloco do poder que estão presentes em seu interior (IBID., p. 135).

O Estado maneja a política a partir de uma série de ações e omissões, de procedimentos contraditórios entre si, no plano concreto das práticas políticas. Realiza uma "seletividade estrutural das informações" conforme a materialidade própria de cada aparelho, garantindo a representação específica de determinados interesses em seu 
interior. Tais interesses dizem respeito ao papel dominante que uma específica fração das classes sociais ocupe em certo período conjuntural (IBID, p. 136). Suas ações representam prioridades e "contra prioridades" respectivas a cada aparelho, rede, setor ou patamar de suas estruturas, segundo a conjunção de forças no interior de cada um. A esta característica soma-se a possibilidade do estabelecimento de contradições entre diferentes parcelas no interior de cada uma das esferas mencionadas. Diante de tal complexidade de interesses, motivações, ações e grupos em seu interior, o Estado exerce uma "filtragem escalonada" para determinar a congruência ou as divergências entre decisões e medidas tomadas em cada aparelho e ramo específico. Esse processo de absorção, reflexão e avaliação seletiva, serve para a tomada de medidas pontuais, conflituais e compensatórias, em face dos problemas mais emergentes no momento, o que materializa a atuação do Estado no jogo de disputas entre os grupos sociais (IBID., p. 136).

Poulantzas conclui que "a política do Estado" se estabelece assim: por meio de um conjunto de atitudes tomadas de forma contraditória, que demonstram, em curto prazo, um forte elemento de incoerência e caos (IBID., p. 137). Contudo, esse caos é parte da complexidade de sua constituição plural, na qual concorrem "feudos, clãs, diferentes facções, em suma, uma multidão de micropolíticas diversificadas" (IBID., p. 138). Essas contradições permeiam seu interior, explicitando clivagens complexas que são comuns aos mais diversos aparelhos.

A estrutura de poder se difunde a partir de redes e hierarquias entre diferentes aparelhos do estado. Ocorre um processo de sobre determinações e resistências entre tais aparelhos, o que produz uma diferenciação importante entre "poder real e poder formal". Determinados aparelhos exercem poder real sobre as determinações econômicas e políticas; já outros apenas manejam estruturas formais em torno da manutenção dos interesses do capital. Sendo assim, a ação do Estado depende, em grande medida, de seu posicionamento frente às classes dominadas; "os aparelhos do Estado consagram e reproduzem a hegemonia ao estabelecer um jogo (variável) de compromissos provisórios entre o bloco no poder e determinadas classes dominadas" (Ibid., p. 140). Além disso, as lutas populares atravessam-no por meio de um encadeamento complexo, que une suas estruturas e o conjunto de dispositivos de poder social, cujo objetivo final é a manutenção do binômio "dominação-subordinação" (Ibid., p. 144). Com essa leitura, Poulantzas inova, já na década de 70, ao identificar a presença das classes populares no interior do Estado, em nichos específicos. Contudo, sua presença no Estado não altera sua posição de classe dominada, e sua ação não significa transformação das estruturas estatais, apesar de ser condição necessária em qualquer processo de ruptura e transição de regime para o socialismo (Ibid., p. 146).

O poder do Estado, manifestado entre as classes, é, portanto uma forma de poder relacional. Os interesses designam-se a partir do "horizonte de ação de uma em relação às ações da outra". O local de poder de uma classe é delimitado pelo espaço ocupado pela outra, sendo assim, o poder não é uma qualidade ontológica de 
determinada classe: depende dos locais materiais e políticos por ela ocupados. O poder de uma classe significa "seu lugar objetivo nas relações econômicas, políticas e ideológicas. Lugar que recobre relações desiguais de dominação/subordinação das classes estabelecidas na divisão social do trabalho, o que significa, então, relações de poder" (Ibid., p. 149). Como esclarece Motta, nesse período, a abordagem foucaultiana tomava lugar das interpretações althusserianas na academia francesa. Sendo o poder uma prática ou uma relação, ele não pode nem ser simplesmente identificado nos sujeitos, nem significar somente as práticas violentas de dominação. Ele atua moldando, normalizando, o que significa controle, mas também, como diz Motta, "positividade" no sentido da possibilidade de resistência. Analisando a formação social capitalista, essa perspectiva relacional de poder permite compreender a reprodução hegemônica do sistema por meio do consenso (Motta 2011a, p. 3)

O Estado não se limita à repressão realizada pelos aparelhos. Tem papel específico na organização das relações ideológicas e na reprodução da ideologia dominante. ${ }^{7}$ A ideologia é uma forma sofisticada de dominação do Estado, que não pode controlar sempre utilizando a repressão e a força. Os aparelhos de Estado passam a ser permeados pelos ditames da ideologia dominante, o que significa o exercício de influência sobre a divisão social do trabalho, da disposição das classes sociais e de seu domínio sobre as demais instâncias do modo de produção (Ibid., p. 28). O Estado introduz-se nas instâncias materiais capitalistas, diretamente na produção do capital, agindo de forma específica para o cumprimento deste papel. Atua na produção de consensos, não no que se refere a um uso simples do termo, mas sim sob a concepção de que trabalha para a hegemonia de classe, garantindo o equilíbrio instável do compromisso entre classes dominantes e dominadas. $O$ Estado torna-se ator de uma série de medidas materiais positivas para as massas populares, mesmo quando estas medidas refletem concessões impostas por sua luta. ${ }^{8}$ Esta leitura parte do pressuposto de que mesmo entre as classes dominantes há disputas e divergências internas, que são manejadas e dirigidas, em grande medida, pela capacidade de controle repressivoideológico do Estado (Ibid., p. 31). Os aparelhos do Estado têm, portanto, a função de materializar as formas hegemônicas de exercício do poder. Contudo, é possível identificar um papel específico, ainda que complexo, na atuação do aparelho judicial, que como se demonstrará a seguir, possui a função de materializar determinadas características essenciais à organização e unificação das disputas relacionais de poder entre as classes dominantes e suas facções, e as classes dominadas (Ibid., p. 386).

\footnotetext{
${ }^{7}$ Segundo o autor, a ideologia não consiste somente num sistema de ideias e representações. Compreende uma série de práticas materiais extensivas aos hábitos, costumes, ao modo de vida dos agentes, e assim se molda como cimento no conjunto das práticas sociais, aí compreendidas as práticas políticas e econômicas. Ver em: Poulantzas, 2000, p. 27. No campo do debate marxista, outras abordagens também releram a perspectiva relacional do poder poulantziana, reforçando o diálogo com a leitura da hegemonia de Gramsci. Ver: (HIRSCH 2005; JESSOP 2006; SAUER 2013; OPRATKO 2014).

${ }^{8}$ Segundo Poulantzas, o Estado também atua de forma prestativa para controlar as massas. Dá exemplos de políticas sociais durante o regime fascista, que procuravam ocultar o aumento da exploração das classes dominadas. Neste sentido, afirma que é necessário identificar as práticas materiais do Estado, a fim de perceber que este não produz repressão somente pela violência ou pela imposição ideológica, mas também interfere na produção de ações materiais para a reprodução da dominação. Ibid., p. 30. Ver também: (BUCKEL 2007; BUCKEL AND FISCHER-LESCANO 2009).
} 
A partir do diagnóstico poulantziano sobre a complexificação das formas de poder e legitimação do Estado capitalista, pode-se observar o processo de expansão do Judiciário como mais um movimento de ampliação das contradições já presentes em seu interior. Na medida em que a inserção de formas participativas promete alterar a lógica procedimental dos tribunais, seria possível afirmar que instrumentos como as audiências públicas jurisdicionais serviriam para potencializar a abertura de espaços aos grupos subalternos para levarem seus pleitos para o interior dos tribunais de forma direta. Essa possibilidade, ainda que motivada por outros fundamentos ideológicos, encontra-se subjacente ao discurso dos ministros do Supremo quando atribuem um papel democratizante à instauração de tais procedimentos. A retórica da democratização e da ampliação da legitimação popular impedem a observação concreta sobre os reais sentidos imprimidos em uma ação de suposta abertura dos aparelhos judiciais. É necessário, portanto, questionar como se materializa esse potencial democrático embutido no conteúdo discursivo proferido a respeito das audiências públicas no STF. Sabe-se, que os aparelhos estatais têm a função de organizar as disputas entre as classes - função repressiva - e de garantir o consentimento ideológico para a manutenção de um equilíbrio entre formas relacionais de poder - controle por meio do consenso. Sendo assim, por mais que se imprima participação social no interior de instâncias tradicionalmente conservadoras, e que, com isso espere-se resultados transformadores, as expectativas precisam ser analisadas de forma controlada. Os aparelhos judiciais manejam a lei que, no Estado capitalista, serve para moldar a materialidade do corpo social sobre o qual age a dominação (MOTTA, 2010, p. 393).

Considerando os conteúdos internos ao Estado capitalista e os tribunais como espaços de litígio e diferenciação de partes e interesses, seria possível falar em deliberação participativa em seus procedimentos? Os participantes das audiências públicas assumem a possibilidade de diálogo e debate deliberativo? Os pronunciamentos por si só significam participação? Deve-se questionar as possibilidades de uma configuração democrática no interior das instituições de justiça. Este trabalho propõe uma tentativa de observação de qual poderia ser um conteúdo democrático dentro das esferas judiciais que coloque em cheque suas estruturas, materializadas no formalismo procedimental, dentro do contexto sócio-político do capitalismo. A análise do direito conforme a teoria poulantziana concorrerá, portanto, para trazer novos questionamentos e parâmetros para o aprofundamento da análise do objeto em questão.

\section{AS FORMAS DO DIREITO E OS APARELHOS JUDICIAIS NO INTERIOR DO ESTADO CAPITALISTA}

O direto tem posição central na formação social capitalista. Em diferentes partes de sua obra, Poulantzas ressaltou aspectos específicos sobre o direito, as leis e as formas de legitimação legal no interior do Estado capitalista. O ponto central de sua observação é o de que o direito passa a exercer um papel objetivo e prático, 
garantindo a coesão entre indivíduos destacados e comprometidos com o exercício de direitos e liberdades específicas, além de garantir um espaço propício para o estabelecimento de relações competitivas em uma sociedade civil de características fragmentadas. Motta, ressalta, nesse sentido, uma vez que o Estado assume sua forma secularizada, passa a depender de uma "codificação normativa abstrata das relações entre indivíduos e vontades comprometidos nas trocas e na competência" (MOTTA, 2010, p. 379). Essa habilidade consiste em um mecanismo que atribui caráter "universal e impessoal" ao Estado, o que se materializa em sua lógica interna, baseada na abstração, generalidade, formalismo e regulamentação (POULANTZAS op. cit., p. 378). Com o objetivo de organizar a sociedade civil, oculta as diferenças presentes em seu interior sob o discurso da legitimidade do interesse geral.

Nesse contexto, a autonomia relativa do Estado fica evidente, posto que tal construção significa a utilização do direito para a reprodução do controle das classes dominadas e mesmo das frações menos proeminentes das classes dominantes. Esse controle, como será aprofundado mais adiante, pode ser feito por concessões às classes dominadas, que, a longo prazo, demonstrem que são interessantes às classes dominantes (IBID, p. 382). Os indivíduos, no interior da sociedade capitalista, são vistos como formalmente livres e iguais, concepção que se reproduz nas teorias liberais da representação política. Esse conjunto de indivíduos desconectados é absorvido pelo discurso unificante do Estado-nação, constructo da ideologia jurídico-política que condensa as diferentes classes sob a ideia de uma comunidade nacional, que é dirigida, representada e controlada pelas classes dominantes, ou mesmo por aquelas mais proeminentes no bloco que dirige e detém o poder do Estado (IBID., p. 383).

Essa configuração do Estado, baseada em uma normatividade jurídico-formal bem determinada, impede a oposição dos indivíduos às determinações estatais. A divisão de poderes no âmbito político consiste em uma formalidade, manejada conforme os interesses conjunturais, que não altera a condição de isolamento entre os indivíduos, mantida pelos primados da igualdade e da liberdade. Muito pelo contrário, serve para que o Estado direcione sua atuação conforme os interesses do bloco de poder (IBID, p. 385). O direito é observado no interior deste modelo como mecanismo formal de estruturação das contradições. Serve como mediador de poder entre classes dominantes e dominadas, assegura a permanência das primeiras nos espaços externos ao poder, sob a produção de uma impressão ilusória de que as classes mais baixas poderiam acender a estes espaços, pois teriam as mesmas oportunidades para tanto. O direito também organiza a repressão física, que será manejada conforme as regras específicas e materializada pela atuação dos aparelhos (MOTTA 2010, p. 386).

Nesse sentido, mais uma vez, as análises sobre o papel do direito se enquadram na observação sobre as características do exercício do poder dominante no interior do Estado capitalista. O direito serve para a organização e unificação dos interesses. Direciona a atuação de seus aparelhos no sentido de promoção desse 
objetivo como a tarefa a ser realizada da forma mais consensual possível. Assim, o caráter ideológico de sua atuação adquire posição privilegiada, posto que o poder se dá prioritariamente de forma relacional, e menos de forma repressiva - ainda que este segundo elemento esteja permanentemente subjacente no interior da atuação política. Portanto, o poder não se reduz ao Estado no marxismo poulantziano. Ele se traduz no sistema das relações entre as classes, pois as relações de produção também se conectam às ligações políticas e ideológicas (IBID, p. 36). O poder, no atual Estado capitalista, está em todas as esferas sociais, sejam públicas ou privadas. Os aparelhos ideológicos e repressivos - burocracia, administração, polícia, Judiciário, escolas, igrejas - materializam a ideologia dominante que se traduz no poder. Realizam tal papel sem ignorar, no entanto, a ocorrência de um processo de disputa entre diferentes sessões das classes dominantes e um jogo permanente de concessões e controle que é exercido em conjunto e sobre as classes dominadas.

O Estado capitalista foi forjado para contrapor a noção de poder ilimitado. A principal implicação desse movimento foi a implementação do binômio lei-terror, ou seja, por meio da legalidade o Estado seria responsável por controlar seus próprios excessos e proteger os cidadãos dos possíveis abusos de poder, na medida em que representa legitimação formal conferida pelo discurso da vontade geral e da proteção equânime de todos os cidadãos (IBID., p. 74). Contudo, essa concepção não se aplica quando se analisam as formulações reais para além do caráter formal do Estado. Poulantzas identifica que todas as formas estatais, mesmo aquelas mais repressoras e autoritárias, utilizaram o primado da lei e a organização jurídica para o exercício de sua prerrogativa de monopólio da violência (Ibid., p. 75).

Poulantzas vai adiante ao observar as formas de detenção do monopólio da violência por parte do Estado. A lei legitima a violência direta por meio de imposições e censuras, mas também a exerce de forma simbólica, por meio de "poder-interdito", manipulando formas de violência ideológico-simbólicas, emanadas de seus diferentes aparelhos e internalizadas pelos indivíduos (Ibid., p. 76). Nesse sentido, as formas de controle ocorrem como se o Estado não necessitasse do uso da força na medida em que detém seu monopólio legítimo. $\mathrm{O}$ consentimento é um processo de "inculcação ideológica", que permite dominar sem exercer a violência diretamente, o que não significa que ela não exista (Ibid., p. 80). E também não significa que não haja resistência e desacordo.

A lei, no Estado capitalista, age de forma paralela; atua para a repressão e organização do consentimento das classes dominadas. Segundo o autor, as classes dominadas veem nas leis dois aspectos que gerem sua ação frente aos aparelhos e ao Estado: atuam para sua exclusão enquanto grupo dominado, mas, também são a forma jurídico-política que designa o lugar onde se inserem na rede político-social. A lei cria deveres e obrigações, cujas consequências são reais para os agentes, e também direitos, "lugar cuja posse originária tem consequências reais" sobre estes sujeitos, cidadãos (Ibid., p. 82). Esse papel serve à justificação de determinadas concessões oriundas do 
bloco de poder, que contribuem para o incremento do consentimento das classes dominadas em torno de uma contenção pacífica exercida pelo Estado de forma difusa sobre suas pretensões.

A partir dessa análise, é possível observar determinados procedimentos que passam a inferir a participação social no interior de instâncias formais do Estado, como os tribunais. A reprodução de consensos é fundamental para a manutenção de uma aparente igualdade formal e universal entre indivíduos fragmentados de acordo com sua posição de classe. Para tanto, não é suficiente a concessão de direitos aos sujeitos, é necessária a complexificação das formas políticas e, por que não, com a expansão dos tribunais, a necessária transformação de determinados aparelhos, entre eles os judiciais, para o manejo de diferentes interesses em seu interior, o que pode ser observado a partir de procedimentos inovadores participativos. Essa "contra leitura" a respeito do potencial democratizante das práticas participativas no interior do Judiciário serve para demonstrar a viabilidade da hipótese lançada nesse trabalho, a de que as audiências públicas jurisdicionais serviriam como procedimentos que sofisticariam as formas de interpretação da Constituição, sem significar uma alteração substancial no papel já tradicionalmente desempenhado pelo sistema de justiça no interior do modo de produção capitalista.

A ação do Estado para a inserção da influência do bloco do poder sobre as diferentes instâncias da totalidade social se dá pelo uso do que se convenciona chamar de "lei moderna". Como desenvolvido em outras interpretações jurídicas a partir do marxismo, ${ }^{9}$ o direito capitalista é classificado como "sistema axiomatizado", dotado de regras abstratas, gerais, formais e estritamente regulamentadas, encobrindo o monopólio da violência institucionalizada, prerrogativa do Estado (IBID., p. 84). Sendo assim, o sistema jurídico exerce o papel fundamental de promover coesão em uma sociedade na qual os indivíduos estão completamente despojados dos meios de produção (SILVEIRA 1984, p. 14).

Dessa forma, a lei acaba por "encarnar" o espaço-tempo do processo de trabalho: espaço-tempo serial, cumulativo, contínuo e homogêneo. Transforma os sujeitos em pessoas jurídicas, produzindo unidade a partir da ideia de "povo nação", pertencente a uma comunidade-território. Isso permite que as diferenças entre os indivíduos, especialmente aquelas que dizem respeito ao espaço ocupado no sistema de produção, sejam mantidas sem prejudicar a formação político-social. Como dito anteriormente, todos os indivíduos são considerados livres e iguais perante a lei, "o que já quer dizer, no discurso da lei (e, não escondido nele), que são realmente diferentes (como sujeitos indivíduos), de forma que essa diferença pode se inscrever num quadro de homogeneidade" (POULANTZAS, op. cit., p. 85). O quadro de homogeneidade é organizado pela lei a partir de uma série de caminhos. Ela oculta, ao mesmo tempo em que instaura e sanciona, a diferença entre indivíduos e classes. Assim, dá seguimento ao processo de individualização, característica fundamental das sociedades 
modernas. A lei torna-se um "signo na representação imaginária da sociedade", servindo para o controle dos indivíduos que são retirados de seus meios naturais de trabalho e produção (IBID., pp. 85-86).

A disseminação da lei abstrata, formal, universal como uma ideologia entre os sujeitos faz parte do processo de emergência de um corpo de juristas especializados, que posiciona os homens do Estado como "homens da lei". Estes passam a ser vistos como aqueles que dominam o conhecimento jurídico, habilidade que, em última instância, é o saber que atua a serviço da manutenção do capital, instaurando a diferença entre público e privado e entre as classes (IBID., p. 88). Nesse contexto, todos são obrigados a conhecer e dominar o conteúdo legal, ainda que sua produção e interpretação sejam mantidas afastadas e sob o monopólio do Estado e de "seus guardiões, aplicadores e fazedores" (IBID., p. 89). A massa da população ignora a lei, ignorância causada pelo próprio hermetismo da linguagem jurídica e possivelmente pelo fechamento dos espaços nos quais se produzem as decisões.

O capitalismo, portanto, possui uma forte identidade com a legalidade. Por ser um sistema que exige reprodução ampliada, faz necessário que sejam bem determinadas e explícitas quais regras irão reger o jogo, para que se produza um mínimo de segurança e estabilidade para os cálculos estratégicos de partes do capital. Assim, suas próprias modificações são reguladas e controladas pelo sistema. A lei exerce a regulação sobre as variações de poder entre a própria burguesia, variações que ocorrem no interior do Estado sem gerar crises excessivas que possam prejudicar a boa circulação e produção de capital. Por essa perspectiva, a lei confere autonomia do Estado em relação aos grupos de poder, ou seja, é uma espécie de barreira que impede a dominação restrita de determinados grupos sobre os aparelhos e estruturas estatais. Isso se deve ao fato da relativa autonomia entre Estado e relações de produção, ou seja, "ao fato de que os agentes da classe economicamente dominante (a burguesia) não se confundam diretamente com os mantenedores e agentes do Estado" (IBID., p. 90).

A análise acerca dos procedimentos de participação no interior do Judiciário, uma vez realizada a partir da abordagem materialista de Poulantzas, permite um olhar crítico que explicite o sentido concreto de tais institutos para além do discurso normativo que os circunda. Isso significa que a abordagem sobre o contexto macrossocial em que se inserem os aparelhos judiciais na atual formação social capitalista sugere a hipótese acerca da impossibilidade de qualquer tipo de democratização por meio das vias judiciais a partir da inserção de participação social em seu interior. Isto se deve ao papel estrutural ocupado pelo direito nestas sociedades, qual seja, seu pressuposto de organizar os interesses contrários entre as classes e produzir consentimento entre os sujeitos jurídico-políticos.

O direito, como parte da política, reproduz no interior de seus aparelhos os conflitos entre as classes, que se materializam no Estado. Contudo, o papel deste conflito é limitado, e em última análise, em resposta a ele, não se pode oferecer mais do que um conjunto de concessões esporádicas, não permanentes e restritas aos limites das 
crises e conjunturas do sistema. Portanto, a democratização participativa para Poulantzas tem conteúdo intrinsecamente conectado com o desenvolvimento de movimentos coletivos autogestionados que posicionem, sobre estas práticas, um processo de crítica radical e transformadora ao próprio espaço no qual se participa. Esgotada a crítica ao direito no modelo poulantziano, é possível observar com reservas o processo de expansão dos tribunais e a potencialidade dos mecanismos de participação em seu interior. A aposta do autor centra-se na democracia direta, formulada em bases de um projeto mais do que reformista. Esse argumento será desenvolvido com mais profundidade no item que segue.

\section{O PROJETO DE UM SOCIALISMO DEMOCRÁTICO}

Como demonstrado anteriormente, a leitura de Poulantzas sobre a democracia passa por uma avaliação crítica a respeito de experiências políticas concretas nas quais foram reveladas características autoritárias e estatistas em regimes europeus. Uma das alternativas que propõe, ao final de sua análise, seria a inserção de um conjunto de procedimentos participativos diretos, que teriam o propósito de controlar as características nocivas presentes no desenvolvimento de regimes políticos, a fim de produzir uma transição democrática rumo ao socialismo (IBID., p. 268). Entretanto, como já afirmado, nem o próprio autor aprofundou o estudo sobre quais características políticas poderiam descrever tal projeto político de "socialismo democrático", o que impede a caracterização dessa categoria como um fim. De toda forma, sua ácida abordagem sobre o Estado capitalista e seus aparelhos servem à análise crítica das formas políticas tradicionais e mesmo daquelas em ascensão, como as práticas pretensamente democráticas no interior dos tribunais.

Segundo Motta, Poulantzas vê baixo potencial, no âmbito do direito, para o exercício do controle em relação à materialização de regimes políticos baseados no autoritarismo estatal. Afirma que justamente por meio da legitimidade da lei, os Estados modernos puderam exercer suas políticas repressivas de forma tão precisa e eficaz. A concepção liberal de direito - universal, abstrato, coerente, regulador e dotado de princípios como igualdade e liberdade - serviu ao controle social devido ao seu "efeito ilusório", disseminado pelo discurso jurídico político. Sendo assim, "toda forma estatal - mesmo a mais totalitária, como o nazismo, e mesmo o estalinismo edificou-se por intermédio da lei e da racionalidade jurídica" (MOTTA 2010, p. 392).

Como descrito no item anterior, a lei possui duas tarefas essenciais nessa formação social: organizar os interesses no interior do bloco de poder - entre classes dominantes e dominadas e em suas fissuras - e garantir o consentimento das classes dominadas a respeito das políticas prioritárias. Realiza tal empreitada por meio da repressão, mas também prevê em seu interior uma série de permissões e concessões que reforçam seu papel de "inculcação ideológica" em torno do consentimento e, principalmente, no entorno das disputas entre posições de poder formal e poder real. Essa última diferenciação torna-se fundamental na medida em que se pretende 
compreender como se daria um processo de ascensão das classes populares ao poder, considerando um avanço político rumo ao socialismo, como diz Poulantzas. A transição para um regime de outro teor parte da construção de uma nova formação social e pressupõe a tomada do Estado. Portanto, a articulação entre poder real e poder formal acaba por significar que a ocupação do poder por um determinado grupo, ainda que com os propósitos mais democráticos e transformadores, não significa um real controle sobre todas as estruturas do Estado.

Nas experiências observadas historicamente, a entrada de governos de esquerda no poder não significou a retirada completa da burguesia do interior de seus aparelhos, muito pelo contrário, foi alcançada mediante articulações e permutas de poder que a mantiveram com certa influência. Isso ocorre porque a "unidade centralizada do Estado não reside numa pirâmide na qual bastaria ocupar o cume para garantir seu controle" (Poulantzas 2000, p. 141). A burguesia dominante funciona por "deslocamentos e substituições sucessivas" que lhe permitem alterar suas posições entre diferentes aparelhos. Tais mutações demandam processos longos, que abrem brechas para atuação tanto das classes dominadas quanto das dominantes, fazendo com que determinados aparelhos institucionais assumam posição central ante posições tradicionalmente secundárias (IBID., p. 142).

$\mathrm{Na}$ tentativa de romper com tais processos políticos, a aposta de Poulantzas é a de que as classes populares devem organizar sua atuação frente ao Estado. Devem manter redes e focos de atuação distantes dos aparelhos do Estado, nos quais possam concentrar movimentos de democracia direta de base e autogestão. Esse movimento de bases coletivas é apresentado por Poulantzas como essencial para que se evitem processos de intervenção excessiva do burocratismo e do controle estatal na definição de suas ações e estratégias, uma vez que estas classes posicionam-se também no interior do Estado (IBID., pp. 156-157).

Para Poulantzas, a teoria política deve passar pela construção de uma teoria do Estado capitalista que permita percorrer um caminho consequente de transição para um socialismo democrático. Com esse objetivo, critica as leituras que escolhem o estatismo. Também critica o sentido leninista de diluição do Estado burguês, que consiste na eliminação das formas de democracia representativa, estabelecendo uma ditadura do proletariado (IBID., p. 255). Neste ponto, retoma as leituras de Rosa Luxemburgo, que defende a importância fundamental das liberdades políticas, uma vez que a falta de debate e de liberdade seriam os primeiros passos para a burocratização e para o estatismo autoritário (IBID, p. 259). Além disso, Poulantzas identifica o elitismo das teorias políticas liberais. Para ele, a democracia representativa desconfia das iniciativas de democracia direta e de iniciativas populares. A leitura burguesa da democracia localiza as classes populares fora do Estado, o qual é visto como um Estado-objeto, cuja racionalidade intrínseca serve para corporificação das práticas políticas da elite por meio dos mecanismos de democracia representativa.

A chave de análise poulantziana sugere a seguinte questão: como compreender "uma transformação radical do Estado" que articule ampliação e aprofundamento das instituições da democracia representativa e das 
liberdades? Que seja capaz de desenvolver formas de democracia direta na base? Que prolifere focos de autogestão? A noção de ditadura do proletariado de Marx foi uma noção estratégica, um indicativo dos possíveis caminhos a traçar, mas ocultou o problema fundamental, qual seja, a articulação de uma democracia representativa transformada e da democracia direta na base. Um dos indicativos de Poulantzas para a solução deste problema, que não chega a desenvolver de forma cristalina, é que a "via democrática para o socialismo é um longo processo no qual a luta das massas populares não visam à criação de um duplo poder efetivo, paralelo e exterior ao Estado, mas aplica-se às contradições internas do Estado" (IBID, p. 262).

A partir do diagnóstico da crise do Estado deve-se procurar a alteração das relações de forças em seu interior, modificando, por consequência, seus aparelhos e dispositivos. Assim, seria possível movimentar as relações de força a favor das massas populares, no campo estratégico de lutas do Estado (IBID., p. 264). De forma complementar, as classes populares devem intensificar o desenvolvimento de modelos de democracia direta e espaços de auto-gestão.

Fica claro que toda a mudança no Estado depende da materialização das mudanças no interior de seus aparelhos. Uma transformação radical do Estado para um socialismo democrático pressupõe a garantia de liberdades políticas a diferentes grupos ideológicos e trata da permanência e continuidade das instituições da democracia representativa. Contudo, a ideia de continuidade tem um conteúdo de ruptura, significa "continuidade não no sentido de uma lamentável sobrevivência que se suporta apenas por não se poder fazer diferente, mas de uma condição necessária para o socialismo democrático". A articulação destes dois processos intervenção e participação interna no Estado, bem como promoção de formas democráticas diretas em seu exterior - é pressuposto para uma "perspectiva global de desaparecimento do Estado" (IBID, p. 268). Também é fundamental para o controle das possibilidades de reação das classes conservadoras.

Como se pode concluir, a leitura da democracia do modelo Poulantziano é bem mais elaborada do que a simplicidade de uma análise institucional e seus conceitos formais acerca dos atributos políticos de um desenho democrático. A interdependência de formas representativas e diretas naquele modelo significa um processo de construção de condições para a dissolução do Estado capitalista tal como se dispõe. Ainda que reconheça um Estado com autonomia relativa, contradições internas, disputa de classes e muito mais complexidade do que um mero reflexo das relações de produção, o modelo de Poulantzas considera o Estado como eminente reprodutor das relações de dominação. Portanto, um caminho para uma democracia participativa a partir do materialismo teria, como pré-requisito, o compromisso em relação ao reconhecimento dos limites intrínsecos às estruturas de um modo de produção que tem por base a exploração e a diferenciação seletiva entre trabalhadores e detentores dos meios de produção. Feito esse alerta, segue-se o item seguinte do argumento deste trabalho, que procura relacionar o papel do direito frente a totalidade do modo de produção capitalista e a atuação procedimental a 
partir de seus aparelhos. Este percurso teórico finaliza a tessitura da hipótese sobre os limites estruturais da democratização participativa no interior das instituições de justiça, especialmente no caso da institucionalização de audiências públicas jurisdicionais no Supremo Tribunal Federal. Para a conclusão, serão trazidos elementos que dialogam com a perspectiva apresentada no sentido de observar potencialidades fruto da repercussão e publicidade gerada pelas audiências públicas para o debate social.

\section{A QUESTÃO: É POSSÍVEL A DEMOCRATIZAÇÃO A PARTIR DAS PRÁTICAS DE PARTICIPAÇÃO SOCIAL NO INTERIOR DOS TRIBUNAIS?}

Como apresentado, o objetivo dessa análise é o de questionar as perspectivas dominantes no discurso a respeito da implementação das reformas e inovações procedimentais no Judiciário brasileiro. Dentre estes, destacam-se as propostas normativas que observam amplo potencial democratizante na inserção de procedimentos participativos no interior dos tribunais. ${ }^{10}$ Não há como não reconhecer a importância de disputar o resultado da decisão judicial, bem como o crescimento das expectativas em torno da ideia de "democratizar" ou "tornar emancipatório" o poder Judiciário. Nesse contexto de esperanças, muitas abordagens de cunho democratizante depositam, na inserção da participação direta ou representativa de agentes externos no interior das instituições de justiça, a possibilidade de que os mais diversos interesses, independentemente do grupo social do qual se originem, sejam considerados na produção de decisões, o que, em última instância, diria respeito à interpretação e conteúdo dos direitos constitucionais e à produção de políticas públicas.

O diagnóstico materialista de Poulantzas permite criticar a leitura otimista a respeito das audiências públicas no Supremo. No interior das estruturas judiciais, manifestam-se os diferentes interesses e contradições comuns as classes sociais. Diferentes grupos, dominantes e dominados, disputam poder dentro do aparelho judicial. Contudo, as características dos aparelhos judiciais reproduzem o conjunto de elementos intrínsecos ao direito moderno: abstração, universalidade, individualismo, formalismo (IBID., p. 78). Nesse contexto, divergências se manifestam em seu interior, podendo obter sucessos provisórios - concessões estratégicas das classes dominantes - o que não significa que tenham potencial transformador. Ao contrário: a atuação dos aparelhos judiciais para a reprodução das posições de poder interessantes ao bloco hegemônico continua sendo mais frequente.

\footnotetext{
${ }^{10}$ Autores como Vianna e Burgos foram precursores nas pesquisas sobre o processo de expansão dos tribunais e a complexificação das relações políticas nas sociedades contemporâneas. Apresentam a "democratização processual progressiva" como chave de análise para a compreensão das possibilidades de disputa no interior das esferas judiciais para a promoção de conquistas de direitos. Certamente, sua análise incorpora uma clara percepção dos limites presentes nas instituições de justiça para a garantia de direitos. Por outro lado, imputa aos agentes, especialmente ao Ministério Público, um potencial de facilitação e promoção de diálogo com a sociedade civil. Ver em: (VIANNA, BURGOS, CARVALHO 1997; VIANNA, BURGOS 2000).
} 
Em suma, Poulantzas defende que a autonomia relativa do Estado frente à economia é um dado concreto, mesmo reconhecendo no Estado uma ossatura permeada de conflitos, e de características materiais que influenciam e são influenciadas pelas diversas instâncias do modo de produção capitalista. Isso significa afirmar que será conferida influência preponderante aos desígnios da reprodução dos interesses do capital. Portanto, pensar sob uma perspectiva crítica os procedimentos que inserem participação no Judiciário significa mitigar as expectativas de que tais institutos possam significar um processo efetivamente transformador das instituições judiciais. Os próprios limites institucionais já evidenciam esse fato, como por exemplo, a discricionariedade dos ministros para decidir sobre a convocação das audiências e utilizar ou não os argumentos lá explanados. Não há compromisso com democratização do Judiciário, apenas inserção formal de espaço para pronunciamentos advindos da sociedade. Na medida em que as audiências públicas significam uma concessão de poder de intervenção por meio da fala técnica ou representativa de interesses coletivos, elas dão aos grupos envolvidos e à sociedade que toma conhecimento de sua realização, a suposta noção de que são agentes efetivamente interventores no processo decisório. Contudo, o poder-real de tomada de decisão não se transfere em parcela alguma a estes grupos. Essa possibilidade não é sequer aventada pelos agentes decisores ou pela legislação que institui tais procedimentos.

Fragale, em análise sobre a audiência pública sobre a ADPF 54, que tratou da questão da antecipação de parto de fetos anencéfalos, traz a perspectiva do debate público gerado em torno das audiências públicas jurisdicionais. Para o pesquisador, as audiências públicas seriam uma "caixa de ressonância de questões moralmente sensíveis", ampliando a repercussão de temas fundamentais na sociedade, muitas vezes pautados pelos movimentos sociais, mas que, somente com a institucionalização do procedimento, conseguem alcançar com força a esfera pública. Contudo, no mesmo sentido levantado nesse trabalho, coloca como hipótese que esse processo não tem influência sobre o processo decisório da corte. Por fim, destaca a necessidade de mais pesquisas empíricas para que essa hipótese possa ser generalizada (FILHO, Fragale 2013).

A conclusão desta análise consiste na verificação de que, dentro das condições estruturais da atual formação social capitalista, quaisquer iniciativas de inserção de participação e transformação social a partir das instituições do Estado apresentam riscos permanentes de formalização em detrimento de mudanças reais. A autonomia relativa das instâncias políticas significa um limite inerente às formas de representação política - ou funcional, ou participativa -, que possam ser concebidas dentro desta estrutura. Nesse sentido, uma efetiva democratização, não do Judiciário, mas da totalidade social, passa por caminhos diferentes dos formalmente concedidos pelas estruturas jurídico-políticas. Este trabalho, com todos os limites de uma análise focada em um objeto específico dentro de um emaranhado de aparelhos, instituições e formas representativas que constituem o Estado capitalista, pretende atentar justamente para tais limites. 
Um discurso de expectativas democratizantes em relação aos compromissos de atuação dos tribunais superiores, materializado na simples convocação e oitiva da sociedade civil, não significa uma efetiva ruptura com o formalismo intrínseco às estruturas dos tribunais. Pelo contrário, torna-se necessário compreender os tribunais como aparelhos inseridos em uma formação social, na qual determinadas características econômicas e políticas exercem influência totalizante sobre os movimentos forjados em seu interior, o que, por si só, já significa uma limitação estrutural importante para a democratização do Judiciário.

Propõe-se, portanto, que o próprio pressuposto de possibilidade de democratização do Judiciário deva ser questionado. Lançando olhar sobre as formas de democracia representativa, é indiscutível que a presença direta de cidadãos nos debates judiciais significa uma mudança procedimental do Judiciário. Todavia, considerando que o próprio conceito de democracia adquire diversos sentidos em diferentes contextos políticos e sociais, cumpre entender que, observadas atentamente as audiências públicas, não se pode falar em mais do que uma mera sofisticação procedimental cujos efeitos são bastante limitados no que diz respeito a produção de impactos democratizantes no interior das estruturas dos tribunais. Portanto, cabe retomar a hipótese apresentada à luz da análise poulantziana: a de que as audiências públicas servem apenas para reestruturação da atuação do Supremo no sentido de garantir uma contenção pretensamente dialética das demandas sociais que, uma vez inseridas em seu interior, são limitadas a um debate formal, cujo impacto participativo é irrelevante para a tomada de decisão dos ministros ou para alteração das formas jurídicas tradicionais aos tribunais.

\title{
SOCIAL PARTICIPATION AND PUBLIC HEARINGS IN BRAZILIAN SUPREME COURT: CONTRIBTIONS SINCE THE POULANTZAS' STATE THEORY
}

\begin{abstract}
:
In this work a review on the discussion about impacts of social participation in the Brazilian Supreme Court (STF) has ben presented. In the first part, the Poulantzas (2000) material theory of state is explicated, which observes the law and its apparatuses as structures that organizing the social body according the priorities of the classes positioning in dominant power block. In this sense, procedures that supposedly promote democracy, like as the public hearings, are interpreted as a simple sophistication of the tribunal's formalism, hiding the control is performed by mechanisms that would grant space to popular participation and would equalize the intervention's opportunities from agents of different social groups. In the second part, based on this analysis of participative practices inside the institution, critical hypothesis about the transference of political processes to judicial sphere in contemporary democratic regimes are presented. Since then the central debate arguments are re-examined, the central conclusions are revisited and the dialogues on the theme are highlighted.
\end{abstract}

Keywords: Brazilian Supreme Court - Public Hearings - Social Participation 


\section{REFERÊNCIAS}

ARNAUD, André-Jean. 1999. O Direito entre a Modernidade e a Globalização. Rio de Janeiro: Renovar.

BUCKEL, Sonja. 2007. Subjektivierung \& Kohäsion. Zur Rekonstruktion einer Materialistischen Theorie des Rechts. Frankfurt: Weilerswist.

BUCKEL, Sonja, Andreas Fischer-Lescano. 2009. "Reconsiderando Gramsci: Hegemonia no Direito Global.” Revista Direito GV5 (2): 471-90.

FRAGALE Filho, Roberto. 2013. “Audiências Públicas e seu Impacto no Processo Decisório: A ADPF 54 como estudo de caso.” In Anais do $37^{\circ}$ Encontro Anual Da ANPOCS, 1-22. Águas de Lindóia: ANPOCS.

HIRSCH, Joachim. 2005. Materialistische Staatstheorie. Transformationsprozesse des kapitalistischen Staatensystems. Hamburg: VSA Verlag.

JESSOP, Bob. 2006. “Kapitalistischer Staatstyp und Autoritärer Etatismus. Poulantzas'Staatstheorie als Moderner

KLASSIKER." In: Lars Bretthauer, Alexander Gallas, John Kannankulam, Ingo Stützle. Poulantzas Lesen. Zur Aktualität Marxistischer Staatstheorie, 48-64. Hamburg: VSA Verlag.

2009a. "Althusser, Poulantzas, Buci-Glucksmannn: Desenvolvimentos Ulteriores Do Conceito Gramsciano de Estado Integral." Crítica Marxista, no. 29: 97-122.

2009b. "O Estado, o Poder, o Socialismo de Poulantzas como um clássico moderno." Revista de Sociologia e Política 17 (33): 131-44.

MARTIN, James. 2008. The Poulantzas Reader. Marxism, Law and the State. Londres: Verso.

MOTTA, Luiz Eduardo. 2009. "Poulantzas e o seu diálogo com Foucault: Direito, Estado e Poder." In $6^{\circ}$ Colóquio Internacional Marx e Engels, 1:1-12. Campinas: Cemarx.

2010. "Poulantzas e o Direito." Dados 53 (2):367-403.

2011 a. "Poulantzas e Foucault: Direito e Estado na perspectiva relacional. Convergências e divergências." In Colóquio Nacional Marx E O Marxismo 2011. Niterói: Niep.

201 1b. "Lei, Estado e Poder: Poulantzas e seu confronto com Kelsen." Revista de Sociologia e Política 19 (38): 7-25. Doi:10.1590/S0104-44782011000100002.

2012. “O (re)começo do Marxismo Althusseriano.” Crítica Marxista, no. 35: 73-89.

OPRATKO, Benjamin. 2014. Hegemonie. Einstiege Bd. 21. Münster: Verlag Westfälisches Dampfboot.

PACHKANIS, Eugeni. 1989. Teoria Geral do Direito e do Marxismo. Rio de Janeiro: Renovar.

POULANTZAS, Nicos. 1969. Clases Sociales y Poder Político en el Estado Capitalista. México: Siglo Veinteuno Editores. 
2000. O Estado, o Poder, o Socialismo. 4 ed. Rio de Janeiro: Paz e Terra.

SAES, Décio. 1998. “A Questão da Autonomia Relativa em Poulantzas.” Crítica Marxista, no. 7: 46-66.

SANTOS, Boaventura de Sousa. 1996. "Os Tribunais nas Sociedades Contemporâneas." Revista Brasileira de Ciências Sociais, no. 30. Http://www.anpocs.org.br/portal/publicacoes/rbcs_00_30/rbcs30_07.htm. 2007. Para uma Revolução Democrática da Justiça. São Paulo: Cortez Editora.

SAUER, Birgit. 2013. 'Putting Patriarchy in its Place'. Zur Analysekompetenz der Regulationstheorie für Geschlechterverhältnisse." In: Roland Atzmüller, Joachim Becker, Ulrich Brand, Lukas Oberndorfer, Vanessa

REDAK, and Thomas Sablowski. Fit Für die Krise? Perspektiven der Regulationstheorie, 111-31. Münster: Verlag Westfälisches Dampfboot.

SILVEIRA, P. 1984. “Poulantzas e o Marxismo.” In: Florestan Fernandes. Poulantzas. Coleção Grandes Cientistas Sociais 47. São Paulo: Ática.

VESTENA, Carolina Alves. 2010. "Participação ou Formalismo? O Impacto das Audiências Públicas no Supremo Tribunal Federal Brasileiro”. Mestrado Profissional em Poder Judiciário, Rio de Janeiro: Fundação Getulio Vargas - Escola de Direito Rio de Janeiro.

2012. "Audiências Públicas: diagnóstico empírico sobre os limites da participação social." Revista Brasileira de Estudos Constitucionais 6 (24): 973-1020.

VIANNA, Luiz Eduardo Werneck, Marcelo Burgos. 2000. "Revolução Processual do Direito e Democracia Progressiva." In: Luiz Eduardo Werneck Vianna, Marcelo Burgos. A Democracia e os Três Poderes no Brasil. Minas Gerais: Editora UFMG.

VIANNA, Luiz Eduardo Werneck, Marcelo Burgos, Maria Alice Resende Carvalho. 1997. Judicialização Da Política E Das Relações Sociais No Brasil. Rio de Janeiro: Revan.

Trabalho recebido aprovado em setembro de 2014. 